\title{
The Impact of Stress, Anxiety, Fear and Depression in The Cause of Cancer in Humans
}

\author{
Sorush Niknamian* \\ Department of Military Medicine, Liberty University, USA
}

*Corresponding author: Sorush Niknamian, Department of Military Medicine, Liberty University, Weston A. Price Foundation (WAPF), PMB 106-380 4200 Wisconsin Avenue, NW Washington, DC 20016, USA.

To Cite This Article: Sorush Niknamian. The Impact of Stress, Anxiety, Fear and Depression in The Cause of Cancer in Humans. Am J Biomed Sci \& Res. 2019 - 3(4). AJBSR.MS.ID.000696. DOI: 10.34297/AJBSR.2019.03.000696

Received: June 08, 2019 | Published: June 25, 2019

\begin{abstract}
Anxiety is an emotion characterized by an unpleasant state of inner turmoil, often accompanied by nervous behavior, such as pacing back and forth, somatic complaints, and rumination. Depression is a state of low mood and aversion to activity that can affect a person's thoughts, behavior, feelings, and sense of well-being. Fear in human beings may occur in response to a specific stimulus occurring in the present, or in anticipation or expectation of a future threat perceived as a risk to body or life. In psychology, stress is a feeling of strain and pressure. Also, this is one type of psychological pain. Cancer as mentioned by Drs. Zaminpira and Niknamian, is an Evolutionary Metabolic Disease (EMHC) which is caused by increasing the amounts of Reactive Oxygen Species (ROS) through the Butterfly Effect (BE) inside human eukaryotic cells. Therefore; increasing inflammation is a promising factor in the cause of cancer. The aim of this review and meta-analysis is to find the link between the depression, stress, fear and anxiety and the possibility of causing cancer. These emotional states have been observed in cancer patients as well. Anxiety and Fear are the two main emotional states which are the side effects of cancer disease, and also, high amounts of emotional stress and depression have been discussed in this review to raise the possibility in causing cancer.
\end{abstract}

Keywords: Anxiety; Fear; Depression; Stress; Cancer; Inflammation; ROS

\section{Introduction}

\section{Depression, Anxiety, Stress and Fear}

Depression is a state of low mood and aversion to activity that can affect a person's thoughts, behavior, feelings, and sense of well-being. A depressed mood is a normal temporary reaction to life events such as loss of a loved one. It is also a symptom of some physical diseases and a side effect of some drugs and medical treatments. Depressed mood is also a symptom of some mood disorders such as major depressive disorder or dysthymia [1].

Anxiety is an emotion characterized by an unpleasant state of inner turmoil, often accompanied by nervous behavior, such as pacing back and forth, somatic complaints, and rumination [2]. It is the subjectively unpleasant feelings of dread over anticipated events, such as the feeling of imminent death [3]. Anxiety is not the same as fear, which is a response to a real or perceived immediate threat, whereas anxiety is the expectation of future threat [4]. Anxiety is a feeling of uneasiness and worry, usually generalized and unfocused as an overreaction to a situation that is only subjectively seen as menacing. It is often accompanied by muscular tension, restlessness, fatigue and problems in concentration. Anxiety can be appro priate, but when experienced regularly the individual may suffer from an anxiety disorder [5].

In psychology, stress is a feeling of strain and pressure. Also, this is one type of psychological pain [6]. Small amounts of stress may be desired, beneficial, and even healthy. Positive stress helps improve athletic performance. It also plays a factor in motivation, adaptation, and reaction to the environment. Excessive amounts of stress, however, may lead to bodily harm. Stress can increase the risk of strokes, heart attacks, ulcers, dwarfism, and mental illnesses such as depression [7].

Fear is a feeling induced by perceived danger or threat that occurs in certain types of organisms, which causes a change in metabolic and organ functions and ultimately a change in behavior, such as fleeing, hiding, or freezing from perceived traumatic events. Fear in human beings may occur in response to a specific stimulus occurring in the present, or in anticipation or expectation of a future threat perceived as a risk to body or life. The fear response arises from the perception of danger leading to confrontation with or escape from/avoiding the threat (also known as the fight-or-flight 
response), which in extreme cases of fear (horror and terror) can be a freeze response or paralysis [8].

In humans and animals, fear is modulated by the process of cognition and learning. Thus fear is judged as rational or appropriate and irrational or inappropriate. An irrational fear is called a phobia. Psychologists such as John B. Watson, Robert Plutchik, and Paul Ekman have suggested that there is only a small set of basic or innate emotions and that fear is one of them. This hypothesized set includes such emotions as acute stress reaction, anger, angst, anxiety, fright, horror, joy, panic, and sadness. Fear is closely related to, but should be distinguished from, the emotion anxiety, which occurs as the result of threats that are perceived to be uncontrollable or unavoidable. The fear response serves survival by generating appropriate behavioral responses, so it has been preserved throughout evolution [9].

\section{Cortisol and Epinephrine}

Cortisol is a steroid hormone, in the glucocorticoid class of hormones. It is produced in humans by the zona fasciculata of the adrenal cortex within the adrenal gland [10]. It is released in response to stress and low blood-glucose concentration. It functions to increase blood sugar through gluconeogenesis, to suppress the immune system, and to aid in the metabolism of fat, protein, and carbohydrates [11].

Epinephrine, also known as adrenalin or adrenaline, is a hormone, neurotransmitter, and medication $[12,13]$. Epinephrine is normally produced by both the adrenal glands and certain neurons. It plays an important role in the fight-or-flight response by increasing blood flow to muscles, output of the heart, pupil dilation, and blood sugar $[14,15]$. It does this by binding to alpha and beta receptors. It is found in many animals and some single cell organisms $[16,17]$.

\section{The Immune System, Cytokines, and Inflammation}

mounting a rapid innate immune system and inflammatory response to a specific trigger and then down regulating the response once a pathogen has been cleared are critical for resolving infection, repairing tissue damage, and returning the body to a state of homeostasis. Recently, however, evidence has accumulated showing that when activation of the inflammatory response is altered or prolonged, it can actually cause more damage to a host than the pathogen itself. Indeed, it is now widely recognized that chronic inflammation plays a role in several major diseases including asthma, arthritis, diabetes, obesity, atherosclerosis, certain cancers, and Alzheimer's disease. One factor that can alter adaptive innate immune system responding and prolong inflammation is stress. In this review, therefore, we consider how stress influences the regulation of inflammation in a way that may be relevant for depression.

The immune system plays a critical role in keeping the body biologically healthy, especially during times of physical injury, wounding, and infection. A key component of this system is the inflammatory response, which is mediated by pro-and anti-inflammatory cytokines that identify, neutralize, and eliminate foreign pathogens such as bacteria and viruses. Inflammation is regulated most proximally by the expression of immune response genes in- cluding IL1B, IL6, and TNF. When activated, these genes promote the secretion of pro-inflammatory cytokines that mediate systemic inflammation. Inflammation is also regulated more distally by processes occurring in the brain, which detects social-environmental cues indicating possible danger. This neuro-inflammatory link is highly adaptive insofar as it can activate the CTRA before a physical injury or bacterial infection takes place. A downside of central regulation of systemic inflammation, however, is that it gives social, symbolic, and anticipated threats-including those that have not yet happened or that may never actually occur-the ability to activate the CTRA in the absence of actual physical threat. Under normal conditions, the SNS up-regulates CTRA-related inflammatory activity via stimulation of $\beta$-adrenergic receptors, and the HPA axis downregulates CTRA-related inflammatory activity via the production of cortisol. However, under conditions of prolonged actual or perceived threat, or possibly during acute stressors indicating social threat or physical danger, glucocorticoid resistance can develop, leading to excessive inflammation that increases a person's risk for several disorders including depression, especially if activation of these pathways is prolonged.

\section{Materials and Methods}

Cortisol can weaken the activity of the immune system. It prevents proliferation of T-cells by rendering the interleukin-2 producer T-cells unresponsive to interleukin-1 (IL-1), and unable to produce the T-cell growth factor (IL-2). Cortisol also has a negative-feedback effect on interleukin-1 [18].

Though IL-1 is useful in combating some diseases, endotoxic bacteria have gained an advantage by forcing the hypothalamus to increase cortisol levels (forcing the secretion of corticotropin-releasing hormone, thus antagonizing IL-1). The suppressor cells are not affected by glucosteroid response-modifying factor [19], so the effective setpoint for the immune cells may be even higher than the setpoint for physiological processes (reflecting leukocyte redistribution to lymph nodes, bone marrow, and skin). Rapid administration of corticosterone (the endogenous type I and type II receptor agonist) or RU28362 (a specific type II receptor agonist) to adrenalectomized animals induced changes in leukocyte distribution. Natural killer cells are affected by cortisol [20].

Cortisol stimulates many copper enzymes (often to $50 \%$ of their total potential), probably to increase copper availability for immune purposes. This includes lysyl oxidase, an enzyme that cross-links collagen, and elastin. Especially valuable for immune response is cortisol's stimulation of the superoxide dismutase, [21] since this copper enzyme is almost certainly used by the body to permit superoxides to poison bacteria.

Cortisol counteracts insulin, contributes to hyperglycemia-causing hepatic gluconeogenesis [22] and inhibits the peripheral use of glucose (insulin resistance) by decreasing the translocation of glucose transporters (especially GLUT4) to the cell membrane [23]. However, cortisol increases glycogen synthesis (glycogenesis) in the liver [24]. The permissive effect of cortisol on insulin action in liver glycogenesis is observed in hepatocyte culture in the laboratory, although the mechanism for this is unknown $[25,26]$. 
As a hormone, epinephrine acts on nearly all body tissues. Its actions vary by tissue type and tissue expression of adrenergic receptors. For example, high levels of epinephrine causes smooth muscle relaxation in the airways but causes contraction of the smooth muscle that lines most arterioles.

Epinephrine acts by binding to a variety of adrenergic receptors. Epinephrine is a nonselective agonist of all adrenergic receptors, including the major subtypes $\alpha 1, \alpha 2, \beta 1, \beta 2$, and $\beta 3$ [27]. Epinephrine's binding to these receptors triggers a number of metabolic changes. Binding to $\alpha$-adrenergic receptors inhibits insulin secretion by the pancreas, stimulates glycogenolysis in the liver and muscle [28], and stimulates glycolysis and inhibits insulin-mediated glycogenesis in muscle $[29,30]$. $\beta$ adrenergic receptor binding triggers glucagon secretion in the pancreas, increased adrenocorticotropic hormone (ACTH) secretion by the pituitary gland, and increased lipolysis by adipose tissue. Together, these effects lead to increased blood glucose and fatty acids, providing substrates for energy production within cells throughout the body [31].

Its actions are to increase peripheral resistance via $\alpha 1$ receptor-dependent vasoconstriction and to increase cardiac output via its binding to $\beta 1$ receptors. The goal of reducing peripheral circulation is to increase coronary and cerebral perfusion pressures and therefore increase oxygen exchange at the cellular level. While epinephrine does increase aortic, cerebral, and carotid circulation pressure, it lowers carotid blood flow and end-tidal $\mathrm{CO}_{2}$ or $\mathrm{ETCO}_{2}$ levels. It appears that epinephrine may be improving macrocirculation at the expense of the capillary beds where actual perfusion is taking place [32].

George M. Slavich and Michael R. Irwin in 2014 concluded that we know a lot about the adverse social-environmental conditions that typically precipitate depression and about cognitive and emotional processes that mediate these effects. With the advent of new neuroimaging, immunological, and genome-wide profiling techniques, we are now poised to go one step deeper and elucidate the full set of biological mechanisms that link stress with depression. Inflammation is undoubtedly a key player in this link. As we have discussed, two general phenomena are consistent with the hypothesis that stress-related increases in inflammation are involved in depression. First, a large number of naturalistic and laboratory-based experimental studies have shown that stress is a potent activator of inflammation, and second, it is now well known that vaccinations and immunological challenges that up-regulate inflammatory activity evoke depressive-like behaviors in rodents and clinically significant episodes of depression in at least some people. In addition, these challenges have been shown to up-regulate peripheral and central cytokine production and to alter metabolic and neural activity in brain regions that have been implicated in depression. Many questions remain unanswered regarding these effects, including whether inflammation is necessary or sufficient for all cases of MDD.

Nonetheless, based on existing data, we conclude that stress likely increases risk for depression in a substantial number of people by up-regulating inflammatory activity and by altering social, cognitive, and affective processes that are known to promote this disorder. These insights are important because they can help update contemporary theories of depression with information about biological mechanisms that are involved in the pathogenesis of MDD. For the potential of these insights to be fully realized, they will need to be translated into new strategies for modifying processes that promote depression (Sanislow et al., 2010). At a very general level, such processes include neurocognitive mechanisms like negative cognitive appraisals and neural sensitivity to social threat, which have been associated with inflammation and depression; immunological processes such as preclinical levels of inflammation, which could presage the development of chronic inflammation and disease; and psychosocial factors such as parental behaviors, which have been found to influence the effects of social-environmental adversity on proinflammatory signaling. The hope is that by targeting these and other dynamics, we may one day be able to reduce the prevalence of depression and the substantial financial burden and personal suffering associated with this common and costly disorder [33].

Sheldon Cohen et al. [34] did a research about stress and disease promotion. In Cohen's first study, after completing an intensive stress interview, 276 healthy adults were exposed to a virus that causes the common cold and monitored in quarantine for five days for signs of infection and illness. Here, Cohen found that experiencing a prolonged stressful event was associated with the inability of immune cells to respond to hormonal signals that normally regulate inflammation. In turn, those with the inability to regulate the inflammatory response were more likely to develop colds when exposed to the virus. In the second study, 79 healthy participants were assessed for their ability to regulate the inflammatory response and then exposed to a cold virus and monitored for the production of pro-inflammatory cytokines, the chemical messengers that trigger inflammation. He found that those who were less able to regulate the inflammatory response as assessed before being exposed to the virus produced more of these inflammation-inducing chemical messengers when they were infected. The immune system's ability to regulate inflammation predicts who will develop a cold, but more importantly it provides an explanation of how stress can promote disease, when under stress, cells of the immune system are unable to respond to hormonal control, and consequently, produce levels of inflammation that promote disease. Because inflammation plays a role in many diseases such as cardiovascular, asthma and autoimmune disorders, this model suggests why stress impacts them as well [34].

Michopoulos V. et al. [35] concluded that the study of inflammation in fear- and anxiety-based disorders has gained interest as growing literature indicates that pro-inflammatory markers can directly modulate affective behavior. Indeed, heightened concentrations of inflammatory signals, including cytokines and C-reactive protein, have been described in posttraumatic stress disorder (PTSD), generalized anxiety disorder (GAD), panic disorder (PD), and phobias (agoraphobia, social phobia, etc.). However, not all reports indicate a positive association between inflammation and fear- and anxiety-based symptoms, suggesting that other factors are important in future assessments of inflammation's role in the 
maintenance of these disorders (i.e., sex, co-morbid conditions, types of trauma exposure, and behavioral sources of inflammation).

The most parsimonious explanation of increased inflammation in PTSD, GAD, PD, and phobias is via the activation of the stress response and central and peripheral immune cells to release cytokines. Dysregulation of the stress axis in the face of increased sympathetic tone and decreased parasympathetic activity characteristic of anxiety disorders could further augment inflammation and contribute to increased symptoms by having direct effects on brain regions critical for the regulation of fear and anxiety (such as the prefrontal cortex, insula, amygdala, and hippocampus). Taken together, the available data suggest that targeting inflammation may serve as a potential therapeutic target for treating these fear- and anxiety-based disorders in the future. However, the field must continue to characterize the specific role pro-inflammatory signaling in the maintenance of these unique psychiatric conditions [35].

Based on evidence that psychological stress may induce a chronic inflammatory process, we hypothesized that the stress caused by chronic fear of terror may be associated with low-grade inflammation. This hypothesis was examined in employed men and women with the presence of low-grade inflammation measured by high sensitivity C-reactive protein (CRP). Apparently healthy employed adults $(\mathrm{N}=1153)$ undergoing periodic health check-ups in a tertiary hospital in Israel completed a questionnaire. Fear of terror (scored 1-5) was assessed by three items measuring the extent to which respondents have deep concern for personal safety, elevated tension in crowded places, and fear of terror strikes causing harm to one's self or one's family members. The main outcome measure was the presence or absence of an elevated CRP level (>3.0 mg/L). Women scored significantly higher on fear of terror compared with men ( $\mathrm{M}=2.16$ vs. $\mathrm{M}=1.68$, respectively; $\mathrm{p}<.0001)$. Most of the study participants who scored high (4 or 5) on fear of terror, reported having experienced this feeling for 1 year or more. In women only, there was a positive association between fear of terror and risk of elevated CRP level (adjusted OR $=1.7,95 \%$ CI 1.2-2.4) in a multivariate model adjusting for generalized anxiety, depressive symptoms, and potentially confounding demographic and biomedical variables. Chronic fear of terror in women, but not in men, is associated with elevated CRP levels, which suggests the presence of low-grade inflammation and a potential risk of cardiovascular disease [36].

Vignes M. et al. \& Bouayed J, et al. [37,38] summarized the data to support a link between oxidative stress and anxiety. While all of the data demonstrate that there is a link between oxidative stress and high-anxiety-related behavior, a cause-effect relationship has yet to be completely established. Some of these studies suggest that oxidative stress causes anxiety-related behaviors but do not explain the underlying mechanisms. While there are some limits in the approach to establish the anxiogenic effect of oxidative stress, the available data are consistent this causal relationship. The potential causal role of oxidative stress on anxiety may generate interest in antioxidants. Masood et al. were able to show that oxidative stress-related anxiety can be reversed in mice upon inhibition of NADPH oxidase or phosphodiesterase-2, enzyme that is indirectly implicated in oxidative stress mechanisms. Surprisingly, they found that diazepam, which is a well-known anxiolytic, does not fully reverse the oxidative stress-related anxiety. These results point to a possible use for antioxidants in the prevention or reduction of high anxiety. Recent work has shown that some dietary polyphenols have both anxiolytic and antioxidant effects, which may be beneficial to anxious subjects $[37,38]$.

It is well known that low/moderate concentrations of reactive oxygen species (ROS) affect a great number of physiological functions [39]. However, when ROS concentration exceeds the anti-oxidative capacity of an organism, animal cells enter a state termed oxidative stress, in which the excess ROS induces oxidative damage on cellular components [40]. As a result, oxidative stress has been implicated in a large range of diseases, including cancer $[41,42]$.

The brain is highly vulnerable to oxidative stress due to its high $\mathrm{O}_{2}$ consumption, its modest antioxidant defenses and its lipid-rich constitution $[43,44]$. Human brain utilizes $20 \%$ of oxygen consumed by the body even though this organ constitutes only about $2 \%$ of the body weight [45]. When the production of oxygen-derived metabolites prevails over the brain defence systems, however, oxidative damage to nucleic acids, proteins and neuronal membrane lipids, which are rich in highly polyunsaturated fatty acids, can occur [46]. In presence of oxidative stress, the lipid-rich constitution of brain favors lipid peroxidation that results in decrease in membrane fluidity and damage in membrane proteins inactivating receptors, enzymes and ion channels. As a result, oxidative stress can alter neurotransmission, neuronal function and overall brain activity [47]. Oxidative stress has been associated with several diseases which are specific for nervous system impairment including neurodegenerative diseases and neuropsychiatric diseases, such as schizophrenia and major depressive disorder [42-44]. The intrinsic oxidative vulnerability of the brain has led some authors to suggest that oxidative damage may be a plausible pathogenic factor for certain neurological diseases including neuropsychiatric disorders [40-46].

\section{Stress and Illness including Cancer}

There is likely a connection between stress and illness. Theories of the stress-illness link suggest that both acute and chronic stress can cause illness, and several studies found such a link [48]. According to these theories, both kinds of stress can lead to changes in behaviour and in physiology. Behavioural changes can be smoking and eating habits and physical activity. Physiological changes can be changes in sympathetic activation or hypothalamic pituitary adrenocorticoid activation, and immunological function [49]. However, there is much variability in the link between stress and illness [50].

Stress can make the individual more susceptible to physical illnesses like the common cold [51]. Stressful events, such as job changes, may result in insomnia, impaired sleeping, and health complaints [52]. Research indicates the type of stressor (whether it's acute or chronic) and individual characteristics such as age and physical well-being before the onset of the stressor can combine to 
determine the effect of stress on an individual. An individual's personality characteristics (such as level of neuroticism) [53], genetics, and childhood experiences with major stressors and traumas [54] may also dictate their response to stressors.

Chronic stress and a lack of coping resources available or used by an individual can often lead to the development of psychological issues such as depression and anxiety [55]. This is particularly true regarding chronic stressors. These are stressors that may not be as intense as an acute stressor like a natural disaster or a major accident, but they persist over longer periods of time. These types of stressors tend to have a more negative impact on health because they are sustained and thus require the body's physiological response to occur daily. This depletes the body's energy more quickly and usually occurs over long periods of time, especially when these microstressors cannot be avoided (i.e. stress of living in a dangerous neighborhood). See allostatic load for further discussion of the biological process by which chronic stress may affect the body. For example, studies have found that caregivers, particularly those of dementia patients, have higher levels of depression and slightly worse physical health than noncaregivers [56].

Studies have also shown that perceived chronic stress and the hostility associated with Type A personalities are often associated with much higher risks of cardiovascular disease. This occurs because of the compromised immune system as well as the high levels of arousal in the sympathetic nervous system that occur as part of the body's physiological response to stressful events [57]. However, it is possible for individuals to exhibit hardiness - a term referring to the ability to be both chronically stressed and healthy. [58]. Many psychologists are currently interested in studying the factors that allow hardy individuals to cope with stress and evade most health and illness problems associated with high levels of stress. Stress can be associated with psychological disorders such as delusions [59], general anxiety disorder, depression, and post-traumatic stress disorder. However, everyone experiences some level of stress, and diagnosis of stress disorders can only be performed by a licensed practitioner. According to a 2016 review article, pathological anxiety and chronic stress lead to structural degeneration and impaired functioning of the hippocampus [60].

It has long been believed that negative affective states, such as feelings of anxiety and depression, could influence the pathogenesis of physical disease, which in turn, have direct effects on biological process that could result in increased risk of disease in the end. However, studies done by the University of Wisconsin-Madison and other places have shown this to be partly untrue; although stress seems to increase the risk of reported poor health, the perception that stress is harmful increases the risk even further $[61,62]$. For example, when humans are under chronic stress, permanent changes in their physiological, emotional, and behavioral responses are most likely to occur [63]. Such changes could lead to disease. Chronic stress results from stressful events that persist over a relatively long period of time, such as caring for a spouse with dementia, or results from brief focal events that continue to be experienced as overwhelming even long after they are over, such as experiencing a sexual assault.
Experiments show that when healthy human individuals are exposed to acute laboratory stressors, they show an adaptive enhancement of some markers of natural immunity but a general suppression of functions of specific immunity. By comparison, when healthy human individuals are exposed to real-life chronic stress, this stress is associated with a biphasic immune response where partial suppression of cellular and humoral function coincides with low-grade, nonspecific inflammation.

Even though psychological stress is often connected with illness or disease, most healthy individuals can still remain disease-free after confronting chronic stressful events. Also, people who do not believe that stress will affect their health do not have an increased risk of illness, disease, or death. This suggests that there are individual differences in vulnerability to the potential pathogenic effects of stress; individual differences in vulnerability arise due to both genetic and psychological factors. In addition, the age at which the stress is experienced can dictate its effect on health. Research suggests chronic stress at a young age can have lifelong impacts on the biological, psychological, and behavioural responses to stress later in life [64].

As stress has a physical effect on the body, some individuals may not distinguish this from other more serious illnesses. Individuals experiencing stress are less likely to see medical care for a symptom if the symptom is ambiguous (e.g. headache) and they are currently experiencing stress. If the symptom is unambiguous however (e.g. a breast lump), and the onset of the stressor is recent, individuals are motivated to seek care as usual [65].

In animals, stress contributes to the initiation, growth, and metastasis of select tumors, but studies that try to link stress and cancer incidence in humans have had mixed results. This can be due to practical difficulties in designing and implementing adequate studies [66].

\section{Discussion}

Fear hormones are secreted by the adrenal gland, an endocrine gland located on top of the kidneys [67]. The fear hormones circulate through the bloodstream to all cells of the body [68]. The effect of adrenaline is similar to the effect of the sympathetic nerve action [69]. Adrenaline increases heart rate, increases breathing rate, dilates blood vessels to the lungs and muscles [70]. Adrenaline also decreases blood flow to the brain and decreases digestion. Cortisol increases blood sugar level by converting stored glycogen and fats into blood sugar. Cortisol also suppresses the immune response and inflammation. Fear hormones result in a longer lasting and more widespread fight-or-flight response than the effects of the nervous system [71-73]. Fear hormone action explains why one may feel the fight-or-flight response even after he/she realize there really is no danger. Daily life can involve many stimuli that are perceived as threatening [74-76]. Problems at work or at school, money or social problems, and medical problems can trigger a chronic (long term) fight-or-flight response. Even anticipating or worrying about things that might happen in the future can trigger the same response as actually experiencing it. Chronic stress occurs when the fight-orflight response does not shut down to allow for the proper balance 
between fear and relaxation. Stress can increase a person's risk of health problems [77-80].

The fight-or-flight response uses calories so the urge to eat makes sense after running. But, eating in response to daily stresses can lead to weight gain and obesity. In addition, stress increases cortisol levels causing elevated blood sugar levels that can lead to both weight gain and diabetes. When the fight-or-flight response causes blood pressure and heart rate to remain high, it puts extra strain on blood vessel walls. As a result, the linings of blood vessels can become damaged and the amounts of oxygen in blood can become lesser than normal $[81,82]$. An interruption of blood flow to the heart can lead to a heart attack. Blood vessels in the brain can also be blocked, resulting in brain-damaging strokes. People suffering from stress secrete cortisol at much higher rates than normal people. There is evidence that abnormally high cortisol levels may actually be the initial trigger for depression in some individuals. High cortisol levels also result in sleep deprivation. Stress also affects the function of the immune system, the body's natural means of fighting off infection. Stressed individuals produce lower levels of antibodies when exposed to pathogens. They also produce higher levels of cytokines, inflammation triggering chemicals secreted when fighting infections. Excessive inflammation is thought to increase the risks for heart disease, diabetes, and cancer. Feeling stressed mentally and physically may have serious health consequences $[83,84]$.

A large literature exists demonstrating that major life events, especially those involving interpersonal loss and social rejection, are a key proximal risk factor for MDD. As it turns out, these stressors have been implicated not just in the development of depression but in the onset, exacerbation, or progression of a variety of health problems. These conditions include several that, like depression, are thought (or known) to be mediated at least in part by inflammation, such as asthma, rheumatoid arthritis, cardiovascular disease, chronic pain, and certain cancers. As a result, we turn now to the question of whether stress is associated with inflammation.

\section{Acknowledgements}

We would like to thank Professor Thomas N. Seyfried at Boston University, Professor Stephanie Seneff the Senior Research Scientist at Massachusetts Institute of Technology (MIT) and Specially Professor Sir John Gurdon at Gurdon Institute for their informative and support. We also would like to thank the Weston A Price Foundation in Washington for their Support.

\section{Conclusion}

Inflammation is partly regulated by the hormone cortisol and when cortisol is not allowed to serve this function, inflammation can get out of control. chronic stress may hamper a naturally occurring anti-inflammatory response in the body. Ordinarily, white blood cells will concentrate in the area of injury or infection where they release chemicals called cytokines to fend off the invaders, a process generally known as inflammation. While inflammation can help fight infection, too much inflammation occurring over time can actually be damaging. Under normal circumstances, the inflammation process is naturally stopped in the body when levels of a stress hormone, cortisol, begin to rise. It is harmful to the body when the inflammation process does not stop as it should. The researchers found that the white blood cells of stressed parents were less responsive to the cortisol hormone, and less likely to shut down an inflammatory response, than the less stressed parents. Their cells kept producing more cytokines. The findings highlight the fact that stress may interfere with the body's ability to shut down its own immune response after it gets started.

Therefore, the bodies of those people suffering from stress may be less likely to regulate their normal defense mechanisms. In conclusion, chronic anxiety, fear and stress results in increasing the hormone cortisol which leads to diabetes, decreasing immune response and increasing inflammation in the tissues which leads to increasing the possibility of cancer incidence. Chronic fear and anxiety increase the hormone adrenaline which decreases the blood flow to the brain and in the long time leads to hypoxia. Therefore; chronic stress, chronic fear and anxiety increase the possibility of cancer incidence basically in the brain. These three chronic disorder cause hypocapnia as well which leads to the hypoxia in body tissues through the Bohr Effect and increases the possibility of cancer incidence in the whole body tissues. In cancer patients, stress, fear, anxiety and depression worsen the disease. Depression alone has not been linked as a factor in causing any types of cancer.

\section{References}

1. (2013) Diagnostic and Statistical Manual of Mental Disorders, (DSM-5). American Psychiatric Association, USA.

2. Seligman MEP, Walker EF, Rosenhan DL Abnormal psychology ( $4^{\text {th }}$ edn), W.W. Norton \& Company, New York, USA.

3. Davison, Gerald C (2008) Abnormal Psychology. Veronica Visentin, Toronto, Canada, p. 154.

4. Vahia VN (2013) Diagnostic and statistical manual of mental disorders 5: A quick glance. Indian J Psychiatry 55(3): 220-223.

5. Bouras N, Holt G (2007) Psychiatric and Behavioral Disorders in Intellectual and Developmental Disabilities. Cambridge University Press, USA.

6. Simandan D (2010) On how much one can take: relocating exploitation and exclusion within the broader framework of allostatic load theory. Health Place 16(6): 1291-1293.

7. Sapolsky Robert M (2004) Why Zebras Don't Get Ulcers. St. Martin's Press, 175 Fifth Ave, New York, USA, pp. 271.

8. Ohman A (2000) Fear and anxiety: Evolutionary, cognitive, and clinical perspectives. In M Lewis, et al. (Eds.). Handbook of emotions, The Guilford Press, New York, USA. pp. 573-593.

9. Olsson A, Phelps EA (2007) Social learning of fear. Nature Neuroscience 10(9): 1095-1102.

10. Scott E (2011) Cortisol and Stress: How to Stay Healthy. About com Retrieved 11-29.

11. Hoehn K, Marieb EN (2010) Human Anatomy \& Physiology. Benjamin Cummings, San Francisco, USA.

12. Lieberman M, Marks A, Peet A (2013) Marks' Basic Medical Biochemistry: A Clinical Approach ( $4^{\text {th }}$ edn).: Wolters Kluwer Health/Lippincott Williams \& Wilkins 175, Philadelphia, USA.

13. (2015) Adrenaline. Guide to Pharmacology IUPS/BPS Retrieved.

14. Bell DR (2009) Medical physiology: principles for clinical medicine ( $3^{\text {rd }}$ edn). Lippincott Williams \& Wilkins 312, Philadelphia, USA. 
15. Khurana (2008) Essentials of Medical Physiology. Elsevier India 460.

16. Buckley E (2013) Venomous Animals and Their Venoms. Venomous Vertebrates. Elsevier 478.

17. (1997) Animal Physiology: Adaptation and Environment (5 ${ }^{\text {th }}$ edn). Cambridge University Press 510.

18. Palacios R, Sugawara I (1982) Hydrocortisone abrogates proliferation of $\mathrm{T}$ cells in autologous mixed lymphocyte reaction by rendering the interleukin-2 Producer T cells unresponsive to interleukin-1 and unable to synthesize the T-cell growth factor. Scand J Immunol 15(1): 25-31.

19. Besedovsky HO, Del Rey A, Sorkin E (1986) Integration of Activated Immune Cell Products in Immune Endocrine Feedback Circuits. In Oppenheim JJ, Jacobs DM, Leukocytes and Host Defense, Progress in Leukocyte Biology, Alan R. Liss, New York, USA, 5: 197-204.

20. Fairchild SS, Shannon K, Kwan E, Mishell RI (1984) T cell-derived glucosteroid response-modifying factor (GRMFT): a unique lymphokine made by normal $\mathrm{T}$ lymphocytes and a $\mathrm{T}$ cell hybridoma. J Immunol 132(2): 821-827.

21. Mavoungou E, Bouyou Akotet MK, Kremsner PG (2005) Effects of prolactin and cortisol on natural killer (NK) cell surface expression and function of human natural cytotoxicity receptors (NKp46, NKp44 and NKp30). Clin Exp Immunol 139(2):287-96.

22. Weber CE (1984) Copper response to rheumatoid arthritis. Med Hypotheses 15(4): 333-48.

23. Flohe L, Beckman R, Giertz H, Loschen G (1985) Oxygen Centered Free Radicals as Mediators of Inflammation. In Sies H Oxidative stress London Orlando pp. 405.

24. Brown DF, Brown DD (2003) USMLE Step 1 Secrets: Questions You Will Be Asked on USMLE Step 1. Hanley \& Belfus, Philadelphia, USA, p. 63.

25. King MB (2005) Lange Q \& A. McGraw-Hill, Medical Pub Division, New York, USA.

26. Baynes J, Dominiczak M (2009) Medical biochemistry. Mosby Elsevier, USA.

27. Shen Howard (2008) Illustrated Pharmacology Memory Cards: Pharmnemonics.

28. Arnall DA, Marker JC, Conlee RK, Winder WW (1986) Effect of infusing epinephrine on liver and muscle glycogenolysis during exercise in rats. Am J Physiol 250(6 Pt 1): E641-649.

29. Raz I, Katz A, Spencer MK (1991) Epinephrine inhibits insulin-mediated glycogenesis but enhances glycolysis in human skeletal muscle. Am J Physiol 260 (3 Pt 1): E430-435.

30. Sabyasachi Sircar (2007) Medical Physiology. Thieme Publishing Group pp. 536.

31. (2010) ANZCOR Guideline 11.5: Medications in Adult Cardiac Arrest. Australian Resuscitation Council Retrieved 7 March 2015.

32. Burnett AM, Segal N, Salzman JG, McKnite MS, Frascone RJ (2012) Potential negative effects of epinephrine on carotid blood flow and ETCO2 during active compression-decompression CPR utilizing an impedance threshold device. Resuscitation 83(8): 1021-1024.

33. Slavich GM, Irwin MR (2014) From Stress to Inflammation and Major Depressive Disorder: A Social Signal Transduction Theory of Depression. Psychol Bull 140(3): 774-815.

34. Cohen S, Janicki Deverts D, Doyle WJ, Miller GE, Frank E, et al. (2012) Chronic stress, glucocorticoid receptor resistance, inflammation, and disease risk. Proc Natl Acad Sci U S A 109(16): 5995-5999.

35. Michopoulos V, Powers A, Gillespie CF, Ressler KJ, Jovanovic T (2004) Inflammation in Fear- and Anxiety-Based Disorders: PTSD, GAD, and Beyond. Psychosom Med 66(4): 484-91.

36. Melamed S, Shirom A, Toker S, Berliner S, Shapira I (2004) Association of fear of terror with low-grade inflammation among apparently healthy employed adults. Psychosom Med 66(4): 484-491.
37. Vignes M, Maurice T, Lanté F, Nedjar M, Thethi K, et al. (2006) Anxiolytic properties of green tea polyphenol (-)-epigallocatechin gallate (EGCG). Brain Res 1110(1):102-115.

38. Bouayed J, Rammal H, Dicko A, Younos C, Soulimani R (2007) Chlorogenic acid, a polyphenol from Prunus domestica (Mirabelle), with coupled anxiolytic and antioxidant effects. J Neurol Sci 262(1-2): 77-84.

39. Valko M, Leibfritz D, Moncol J, Cronin MTD, Mazur M (2007) Free radicals and antioxidants in normal physiological functions and human disease. Int J Biochem Cell Biol 39(1): 44-84.

40. Delattre J, Beaudeux JL, Bonnefont Rousselot D (2005) Radicaux libres et stress oxydant. Aspects biologiques et pathologiques. Éditions Médicales internationals pp. 1-492.

41. Aitken RJ, Roman SD (2008) Antioxidant systems and oxidative stress in the testes. Oxid Med Cell Longev 1(1): 15-24.

42. Halliwell B (2006) Oxidative stress and neurodegeneration: where are we now? J Neurochem 97(6):1634-1658.

43. Clarke DD, Sokoloff L (1999) Circulation and energy metabolism of the brain. In: Sigel GJ, et al. [Eds.], Basic neurochemistry: molecular, cellular and medical aspects. Lippincott-Raven, Philadelphia, USA, pp. 637-669.

44. Lebel C, Bondy SC (1991) Oxygen radicals: Common mediators of neurotoxicity. Neurotox Teratol 13(3): 341-346.

45. Cardozo PF, Song S, Parthasarathy A, Hazzi C, Naidu K, et al. (1999) Oxidative DNA damage in the aging mouse brain. Mov Disord 14(6): 972-980.

46. Bilici M, Efe H, Koroglu MA, Uydu HA, Bekaroglu M, et al. (2001) Antioxidative enzyme activities and lipid peroxidation in major depression: Alterations by antidepressant treatments. J Affect Disord 64(1): 43-51.

47. Yao JK, Reddy RD, Kammen DP (2001) Oxidative damage and schizophrenia: an overview of the evidence and its therapeutic implications. CNS Drugs 15(4): 287-310.

48. Schneiderman N, Ironson G, Siegel SD (2005) "Stress and health: psychological, behavioral, and biological determinants". Annual Review of Clinical Psychology 1: 607-628.

49. Herbert TB, Cohen S (1993) "Stress and immunity in humans: a metaanalytic review". Psychosomatic Medicine 55(4): 364-379.

50. Ogden J (2007) Health Psychology: a textbook ( $4^{\text {th }}$ edn), McGraw-Hill, New York, USA. pp. 281-282.

51. Cohen S, Doyle WJ, Skoner DP, Rabin BS, Gwaltney Jr JM (1997) Social ties and susceptibility to the common cold. JAMA: the journal of the American Medical Association 277(24): 1940-1944.

52. Greubel, Jana, Kecklund, Göran (2011) The Impact of Organizational Changes on Work Stress, Sleep, Recovery and Health. Industrial Health 49(3): 353-364.

53. Jeronimus BF, Riese H, Sanderman R, Ormel J (2014) Mutual Reinforcement Between Neuroticism and Life Experiences: A Five-Wave, 16-Year Study to Test Reciprocal Causation. Journal of Personality and Social Psychology 107(4): 751-64.

54. Jeronimus BF, Ormel J, Aleman A, Penninx BWJH, Riese H (2013) Negative and positive life events are associated with small but lasting change in neuroticism. Psychological Medicine 43(11): 2403-2415.

55. Schlotz W, Yim IS, Zoccola PM, Jansen L, Schulz P (2011) The perceived stress reactivity scale: Measurement invariance, stability, and validity in three countries. Psychol Assess 23(1): 80-94.

56. Pinquart M, Sörensen S (2003) Differences between caregivers and noncaregivers in psychological health and physical health: a metaanalysis. Psychology and aging 18(2): 250-267.

57. Margaret E Kemeny (2003) The Psychobiology of Stress in Current Directions in Psychological Science. 12(4): 124-129. 
58. Kobasa SC (1982) The Hardy Personality: Toward a Social Psychology of Stress and Health. In GS Sanders, et al. (Ed's.). Social Psychology of Health and Illness, Hillsdale, NJ: Lawrence Erlbaum Assoc, USA. p. 1-25.

59. Kingston C, Schuurmans Stekhoven J (2016) Life hassles and delusional ideation: Scoping the potential role of cognitive and affective mediators. Psychology and Psychotherapy 89(4): 445-463.

60. Mah L, Szabuniewicz C, Fiocco AJ (2016) "Can anxiety damage the brain?". Curr Opin Psychiatry 29(1): 56-63.

61. Keller A, Litzelman K, Wisk LE, Maddox T, Cheng ER, et al. (2012) “Does the perception that stress affects health matter? The association with health and mortality". Health Psychol 31(5): 677-684.

62. (2013) Stress as a positive: Recent research that suggests it has benefits.

63. Cohen S, Janicki Deverts D, Miller GE (2007) Psychological Stress and Disease. JAMA 298(14): 1685-1687.

64. Miller G, Chen E, Cole SW (2009) Health psychology: Developing biologically plausible models linking the social world and physical health. Annual Review of Psychology 60: 501-524.

65. Cameron L, Leventhal EA, Leventhal H (1995) Seeking medical care in response to symptoms and life stress. Psychosomatic Medicine 57(1) 37-47.

66. Hargrove MB, Nelson DL, Cooper CL (2013) Generating eustress by challenging employees: Helping people savor their work. Organizational Dynamics 42(1): 61-69.

67. Weinberger DR (2001) Anxiety at the frontier of molecular medicine. N Engl J Med 344(16): 1247-1249.

68. Leman S, Le Guisquet A, Belzung C (2004) Liens anxiété-mémoire: Études expérimentales. In: Ferreri M, editor. Dans: "Anxiété, anxiolytiques et troubles cognitifs", Elsevier, Paris, France. p. 71-79.

69. Gross C, Hen R (2004) The developmental origins of anxiety. Nat Rev Neurosci 5(7): 545-552.

70. Kessler RC, Berglund P, Demler O, Jin R, Merikangas KR, et al. (2005) Lifetime Prevalence and Age-of-Onset Distributions of DSM-IV Disorders in the National Comorbidity Survey Replication. Arch Gen Psychiatry 62(6): 593-602.

71. Lépine JP (2002) The epidemiology of anxiety disorders: prevalence and societal costs. J Clin Psychiatry 63(Suppl 14): 4-8.

72. Alonso J, Lépine JP (2007) Overview of key data from the European Study of Epidemiology of Mental Disorders (ESEMeD). J Clin Psychiatry 68(Suppl 2): 3-9.
73. Alonso J, Angermeyer MC, Bernert S, Bruffaerts R, Brugha TS, et al. (2004) Prevalence of mental disorders in Europe: results from the European Study of the Epidemiology of Mental Disorders (ESEMeD) project. Acta Psychiat Scand 109(420): 21-27.

74. Wittchen HU, Jacobi F (2005) Size and burden of mental disorders in Europe-a critical review and appraisal of 27 studies. Eur J Neuropsychopharmacol 15(4): 357-376

75. Tuthill A, Slawik H, O’Rahilly S, Finer N (2006) Psychiatric co-morbidities in patients attending specialist obesity services in the UK. QJM: Monthly Journal of the Association of Physicians 99(5): 317-325.

76. Eisenberg DM, Davis RB, Ettner SL, Appel S, Wilkey S, et al. (1998) Trends in alternative medicine use in the United States, 1990-1997: Results of a follow-up national survey. JAMA 280(18): 1569-1575.

77. de Graaf R, Bijl RV, Smit F, Vollebergh WAM, Spiker J (2002) Risk factors for 12-month comorbidity of mood, anxiety and substance use disorders: Findings from the Netherlands Mental Health Survey and Incidence Study. Am J Psychiatry 159(4): 620-629.

78. Issakidis C, Andrews G (2002) Service utilisation for anxiety in an Australian community sample. Social Psychiatry and Psychiatric Epidemiology 37(4): 153-163.

79. Kuloglu M, Atmaca M, Tezcan E, Gecici O, Ustundag B, et al. (2002) Antioxidant enzyme and malondialdehyde levels in patients with panic disorder. Neuropsychobiology 46(4): 186-189.

80. Kuloglu M, Atmaca M, Tezcan E, Gecici O, Tunckol H, et al. (2002) Antioxidant enzyme activities and malondialdehyde levels in patients with obsessive-compulsive disorder. Neuropsychobiology 46(1): 27-32.

81. Valko M, Leibfritz D, Moncol J, Cronin MTD, Mazur M, et al. (2007) Free radicals and antioxidants in normal physiological functions and human disease. Int J Biochem Cell B 39(1): 44-84.

82. Delattre J, Beaudeux JL, Bonnefont Rousselot D (2005) Radicaux libres et stress oxydant. Aspects biologiques et pathologiques. Éditions Médicales internationals, pp. 1-492.

83. Aitken RJ, Roman SD (2008) Antioxidant systems and oxidative stress in the testes. Oxidative Medicine and Cellular Longevity 1(1):15-24.

84. Ng F, Berk M, Dean O, Bush AI (2008) Oxidative stress in psychiatric disorders: Evidence base and therapeutic implications. Int J Neuropsychopharmacol 11(6): 851-876. 